\title{
Overview of Existing Electricity Tariff Structure \& Residential Load Pattern in Maharashtra: A Case Study
}

\author{
${ }^{* 1}$ Archana S. Talhar, ${ }^{2}$ Sanjay B. Bodkhe, ${ }^{3}$ Apurva Ambade, ${ }^{4}$ Laxmankumar S. Belge \\ ${ }^{1,2,3}$ Shri Ramdeobaba College of Engineering and Management, Nagpur \\ ${ }^{4}$ Capgemini Mumbai, India \\ Email: ${ }^{1}$ archanabelge2@gmail.com, ${ }^{2}$ bodkhesb@rknec.edu, ${ }^{3}$ ambadeapurva@gmail.com, \\ ${ }^{4}$ laxmankumar.belge@capgemini.com
}

Received: 06th October 2019, Accepted: 20th November 2019, Published: 31st December 2019

\begin{abstract}
Use of energy sensibly, based on the availability of Time of Day (ToD) tariff, is the most important tool in demand side management. ToD offers a variety of prices at different time intervals and generally remains same for all seasons. This paper presents an overview of electricity tariff structures, objectives of tariff policy, slab wise tariff structure, major components of electricity tariff and reason for tariff hike in Maharashtra state. It is observed that the slab wise tariff is compulsory for residential consumers whereas ToD tariff is compulsory for non-residential consumers. Due to the modern lifestyle, energy consumption of residential consumers is also increasing; so now onwards, the slab wise tariff will not work for controlling electricity bill. The right solution will be ToD tariff, which is already available but only for non-residential consumers. Therefore, a survey is carried out in Nagpur, Maharashtra State, to verify up to what extent, the actual residential load consumption pattern, matches with the existing ToD slots of sample utility. Maharashtra State Electricity Distribution Company Limited (MSEDCL) was considered as it is one of the old and major utility serving the Maharashtra. During this survey, it is found that in winter and rainy seasons, the residential load curve matches more than $90 \%$ with the existing ToD slots. Whereas, in the summer season, the match is very less. Hence, based on the actual survey data, this paper proposes new ToD slots for residential consumers.
\end{abstract}

\section{Keywords}

Electricity Cost, Load Curve, Residential Load, Slab Wise Tariff, ToD Tariff.

\section{Introduction}

The electricity cost is divided into two parts: $1^{\text {st }}$ part is static cost (fixed) and the $2^{\text {nd }}$ part is dynamic cost (variable). It is also called as Two Part Tariff. Static cost consists of funding cost i.e. interest on loan capital, interest on working capital, depreciation cost, return on equity (profit), operation \& maintenance expenses, income tax, tax liabilities of power generation, transmission and distribution network etc. This static cost is recovered from fixed charges or demand charges in accordance with Electricity Act (EA) 2003 and National Tariff Policy. The dynamic cost includes the fuel cost, operation and maintenance cost, cost of electricity purchased from other utilities, cost of power lost in transmission \& distribution, state levies such as surcharge, tax, etc. This dynamic cost is recovered from energy charges [1] - [2].

The tariff policy has been established in consultation with the State Governments, Central Electricity Authority (CEA), Central Electricity Regulatory Commission (CERC) and recommendations of various shareholders. The aim of tariff policy is to: 1) ensure the availability of electricity to consumers at reasonable and competitive rates 2) ensure the financial viability of the sector and attract investments 3) promote transparency, consistency and predictability in regulatory approaches across jurisdiction and minimize perceptions of regulatory risk 4) promote competition, efficiency in operations and improvement in quality of supply [3]- [4]

In Maharashtra, the electricity tariff is mainly slab wise. The objective behind the slab wise tariff structure is to charge less from low energy consumers and charge more to high energy consumers. The slab wise tariff in Maharashtra state consist of various components like fixed charges, wheeling charges, electricity duty, taxes, fuel adjustment charge and the energy charges [5] - [7].

A. Fixed charges: This includes installation and maintenance of meter, billing, customer service, complaints, etc. Therefore, a consumer need to pay fixed charges, even if the consumer does not use any units of electricity.

B. Wheeling charges: This include transmission/transportation charges of energy from generating station to the consumer site. Normally generation plants are located at remote area and the utility needs to transmit power over long distances through transmission company. The distribution company has to pay the transportation charges to the transmission company in the form of wheeling charges which are recovered from consumers. The wheeling charges are levied as per the voltage level on which the consumer is connected. The logic is, if the consumer is connected to the higher voltage level, transmission and wheeling losses will be less and vice - versa. Therefore, connecting consumers to the higher voltage level is beneficial to utility.

C. Electricity Duty, Tax on Sale of Electricity: The electricity cost consisting of static \& variable cost, is referred as base charges. The consumer has to pay additional charges above the base charges which are imposed by the Government or other competent authorities. e.g. Electricity Duty and Tax on Sale of Electricity. It will be charged in addition to the base charges approved by 
the Commission, Government guidelines. A government circular regarding this is always mentioned in the electricity bill with effective date.

D. Fuel Adjustment Charge (FAC): In addition to base charges and duties/tax, consumer needs to pay fuel adjustment charges also as approved by the Commission from time to time. This is applicable to all categories of consumers. These charges include basic fuel cost, its transportation cost by rail/road/pipeline or any other means for bringing fuel up to the Power Station boundary. It also includes fuel treatment charges such as washing/cleaning charges, sizing crushing charges, fuel analysis charges etc. for making fuel up to the required grade/quality.

E. Energy Charges: For the LT - I (B) residential consumer, the regulatory authority has recommended the slab wise tariff for energy charges as shown in Table 1 (a).

\section{Reason for Tariff Hike}

Hike in electricity tariff normally takes place due to following reasons [3]:

- Increase in capital expenditure, increase in the expense towards depreciation, long term loans, return on equity, etc.

- True - up of additional expense for previous years.

- Increase in power purchase costs due to increased demand.

- Revenue gap due to the deviation in the estimated and approved revenue.

- Impact of orders from various regulatory authorities.

- Burden on utility due to approved revenue.

Tariff Structure of Low Tension (LT) and High Tension ( HT) Consumers in Maharashtra

The LT consumers are of two types: 1) LT - I residential consumers; here electricity is used at low/medium voltage for operating various appliances such as lighting, heating, cooling, cooking, washing/cleaning, entertainment, water pumping etc. 2) LT - II non residential consumers; here electricity is used for the same purpose as in LT - I, but in non-residential premises, commercial and business premises which includes shopping malls and showrooms. For these LT consumers, slab wise tariff is compulsory whereas, the ToD tariff is optional to LT - II non- residential consumers. In ToD tariff, the price of energy changes with change in time period e.g. during the peak period, energy charges are very high; during off peak period energy charges are very low; and so on.

HT consumers are big consumers like Industrial (general/seasonal), commercial, public water works \& sewage treatment plant, public services. Energy consumption is high in this group of consumers, so they have to pay ToD charges in addition to the base charges. Depending upon the time of use of energy, consumers will get a rebate or penalty in the electricity bill. The ToD charges for LT - II non-residential and HT consumers of MSEDCL is shown in Table 1 (b).

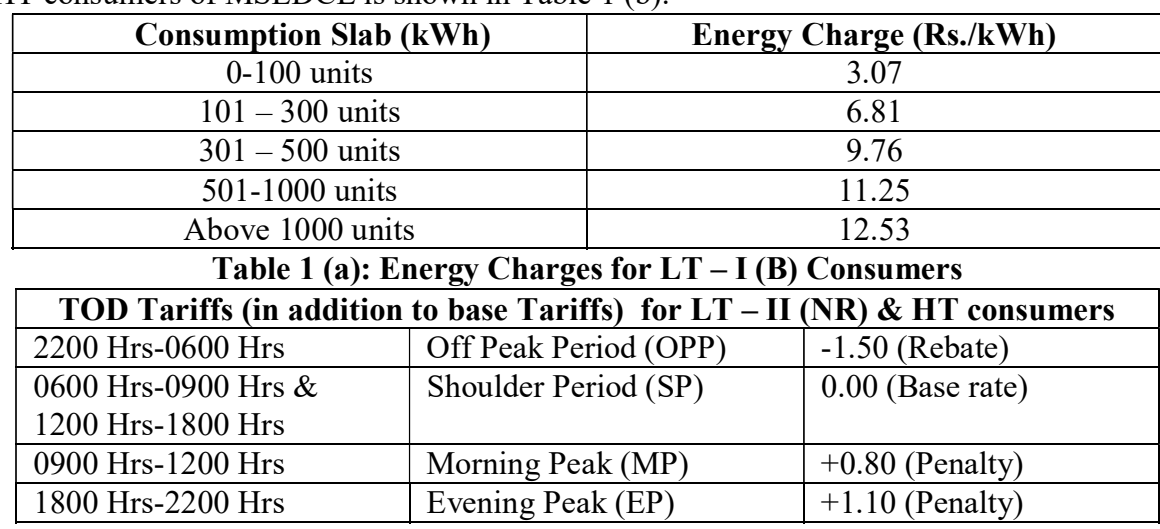

Table 1 (b): ToD Charges for LT - II (B) (Non Residential) \& HT Consumers

The ToD time slots are labeled as: (2200 Hrs-0600 Hrs): Off peak period (OPP); (0600 Hrs-0900 Hrs \& $1200 \mathrm{Hrs}-1800 \mathrm{Hrs})$ : Shoulder period (SP); (0900 Hrs-1200 Hrs): Morning Peak (MP) and (1800 Hrs-2200 Hrs): Evening Peak (EP). ToD rates are optional for LT - II non - residential consumers and mandatory for HT consumers. The objective behind the ToD tariff is to shift the load from peak to off-peak hours and avoid spikes in the demand pattern [9]- [11].

As discussed earlier, energy tariff is slab wise for the residential load. This slab wise tariff is made, by keeping in mind the economically poor class of society. Since this class has less number of electrical devices, so energy consumption is less and need not to pay at a higher rate. But in that case, middle class group of society has no encouragement for optimal utilization of electricity or use of energy with a responsibility. The only way is to reduce energy consumption. But for reducing energy consumption, a consumer cannot be asked to restrict the use of household appliances. These are not the measures for reducing electricity bill in present circumstances. So the right solution would be per day time of day tariff. A consumer should switch on that particular load during the off peak hours to get benefited and the load on the grid, during peak hours also gets reduced. It will be a win-win situation for both 
i.e. consumer and utility. Those consumers not following this pattern will have to pay a higher price. This will improve the awareness for conservation and use of energy with responsibility because of the various advantages: 1) Reduction in the Energy bill 2) Load on the grid during peak hours will reduce, due to which the cost of energy generation or the capital cost required to install new capacities of generation for supply during peak load will get reduced 3) Since the power generation during peak hours is reduced, fuel consumption during peak hours will also reduce which ultimately results in the low carbon emission.

Therefore, a survey is carried out to verify up to what extent the actual residential load consumption pattern matches with the existing time of day slots for one of the utility in Maharashtra state. During this survey it is observed that in Maharashtra, four utilities are serving electricity. Being one of the old and major utility serving the Maharashtara, MSEDCL is considered. This utility supplies power in four regions of Maharashtra: 1) Konkan region 2) Aurangabad region 3) Pune region and 4) Nagpur region. Out of these four regions, Nagpur region is considered for the survey which is discussed in next section.

\section{Materials and Methods}

In Maharashtra, power system is divided into two parts: Mumbai and the rest of the Maharashtra. Mumbai is served by Reliance power, TATA power, BEST power whereas the rest of Maharashtra is served by MSEDCL [8]. The tariff structure of all utilities is approximately same i.e. slab wise tariff for residential consumers and ToD tariff for non-residential consumers [9] - [14]. To observe the actual residential load pattern of Maharashtra state, a survey of MSEDCL is carried out. Till December 2018, MSEDCL is having only $0.09 \%(22,524)$ High Tension (HT) consumers, out of total connected consumers $(2,44,21,258)$ whereas $99.91 \%(2,43,98,754)$ of Low Tension (LT) consumers. The different category of MSEDCL consumers count with the percentage as shown in Table 2 (a) [6]. The share of energy consumption of all connected consumers is shown in Table 2 (b). Out of all categories, residential consumer is the $3^{\text {rd }}$ largest consumer in energy consumption.

\begin{tabular}{|l|l|l|}
\hline Type of Consumers & Count & \% of Consumers out of Total \\
\hline Residential & 18533733 & 75.89 \\
\hline Commercial & 1805728 & 7.39 \\
\hline LT-Industrial & 384633 & 1.57 \\
\hline Agricultural & 3400191 & 13.92 \\
\hline LT-Other & 274469 & 1.12 \\
\hline HT & 22504 & 0.09 \\
\hline Total & $\mathbf{2 4 4 2 1 2 5 8}$ & $\mathbf{1 0 0 . 0 0}$ \\
\hline
\end{tabular}

Table 2 (a): Connected Consumers till December 2018

\begin{tabular}{|l|l|l|}
\hline Type of Consumers & $\begin{array}{l}\text { Share in Energy } \\
\text { Consumption (MU's) }\end{array}$ & Share in \% \\
\hline Residential & 1394.73 & 13.95 \\
\hline Commercial & 433.25 & 4.33 \\
\hline LT-Industrial & 712.27 & 7.12 \\
\hline Agricultural & 4468.45 & 44.69 \\
\hline LT-Other & 268.93 & 2.69 \\
\hline HT & 2721.4 & 27.22 \\
\hline Total & $\mathbf{9 9 9 9 . 0 3}$ & $\mathbf{1 0 0 . 0 0}$ \\
\hline
\end{tabular}

Table 2 (b): Share in Energy Consumption of Consumers till December 2018

During this research work, a survey is carried out in the Nagpur region of the Nagpur zone. The study of outgoing feeders of one of the substation of Nagpur zone having more than $90 \%$ of the residential load is carried out. On some feeders, hourly residential load consumption is captured in Megawatt (MW) and in some cases in terms of load current in Amperes (A). The data is recorded for all the seasons i.e. summer, winter and rainy season. The monthly, hourly energy consumption data of residential consumers is available on MSEDCL website [15]. Three different locations were identified for this survey 1) Din Dayal Nagar 2) Trimurti Nagar and 3 ) Congress Nagar. The hourly load consumption data for summer season, winter season and rainy season is as shown in Fig. 1 to Fig. 3. It is observed that in winter and rainy seasons, the residential load curve matches more than $90 \%$ with ToD slots of MSEDCL LT -II (B) non-residential consumer whereas, in the summer season, the match between them is very less.

As per discussion in the previous section, to reduce the electricity bill of residential consumers, slab wise tariff will not work. The only solution is Time of Day tariff. Hence, depending upon the time of use of electricity, the consumer will get rebate or penalty in electricity bill. Planning the load sensibly will result a consumer in rewards in terms of rebate in electricity bill, and those consumers not opting for this may end up paying penalty. 


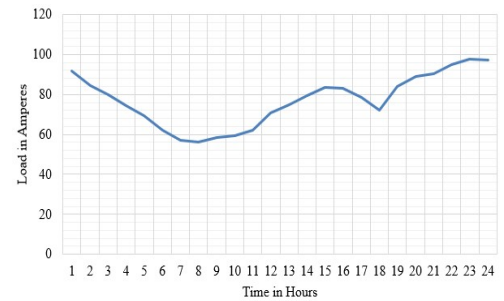

(a)

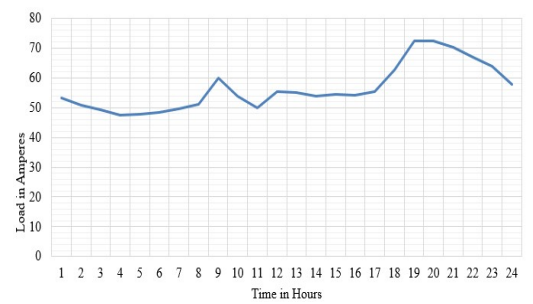

(b)

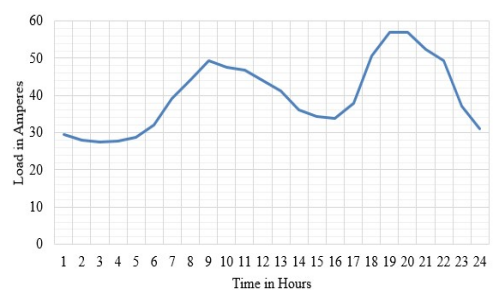

(c)

Figure 1: Electricity Consumption of Din Dayal Nagar

(a) During Summer Season, (b) During Winter Season, (c) During Rainy Season

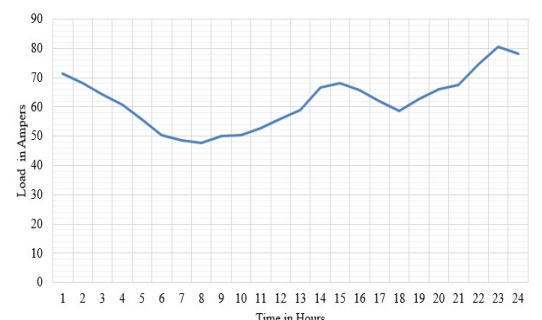

(a)

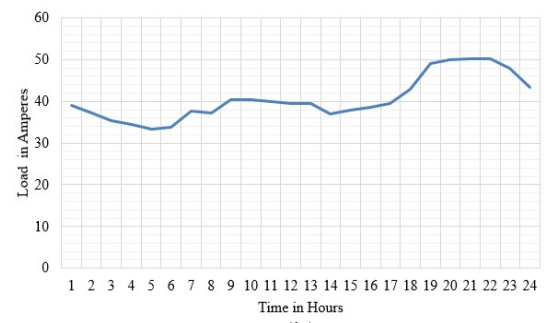

(b)

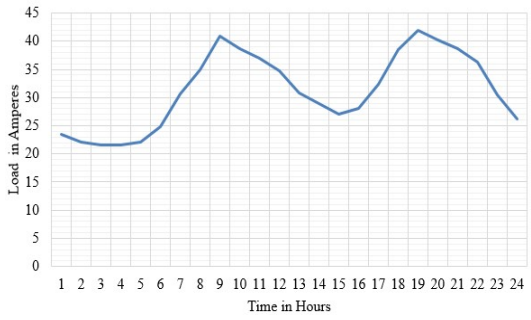

(c)

Figure 2: Electricity Consumption of Trimurti Nagar

(a) During Summer Season, (b) During Winter Season, (c) During Rainy Season

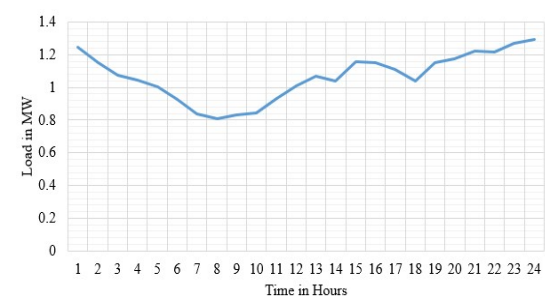

(a)

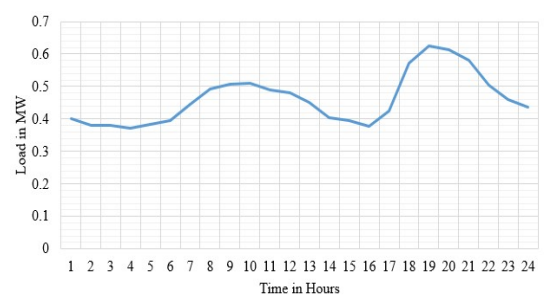

(b)

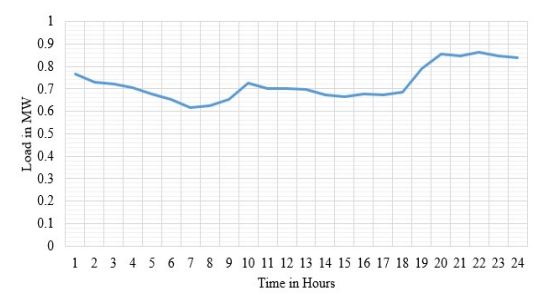

(c)

Figure 3: Electricity Consumption of Congress Nagar

(a) During Summer Season, (b) During Winter Season, (c) During Rainy Season

\section{Results and Discussion}

A survey is carried out to understand the load consumption pattern of residential consumers of the Nagpur zone for summer, winter and rainy seasons. It is observed from Fig. 1 to Fig. 3 that $90 \%$ load consumption curve in winter and rainy season is similar to the MSEDCL's existing ToD slots of LT (II) non-residential consumer. This is shown in Table 3 and 4 . Whereas; the scenario is totally different in case of the summer season. It is observed from summer season load curve that evening peak period in existing structure becomes night peak, morning peak becomes the afternoon peak and shoulder period and off peak period are changed as shown in Table 5. The sign ' $\sqrt{ }$ ' indicates that the time of day period is similar to the ToD slot of MSEDCL. Wherever the slots are not same, actual load consumption period is mentioned. The proposed ToD slots are mentioned in Table 6. 


\begin{tabular}{|c|c|c|c|}
\hline Existing ToD Slots of MSEDCL LT -II (B) non- & \multicolumn{3}{|c|}{ Observed period of variation in load curve } \\
\hline Time Slots in Hours & $\begin{array}{l}\text { Din Dayal } \\
\text { Nagar }\end{array}$ & Trimurti Nagar & $\begin{array}{l}\text { Congress Nagar } \\
\text { division }\end{array}$ \\
\hline 2200 Hrs. -0600 Hrs. & $\sqrt{ }$ & $\sqrt{ }$ & $\sqrt{ }$ \\
\hline $\begin{array}{l}0600 \text { Hrs. }-0900 \text { Hrs. } \\
1200 \text { Hrs. }-1800 \text { Hrs. }\end{array}$ & $\begin{array}{ll}0600 & \text { Hrs. } \\
- & 0800 \\
\text { Hrs. } & \\
\sqrt{ } & \end{array}$ & $\begin{array}{l}0600 \text { Hrs. }-0800 \\
\text { Hrs. } \\
\sqrt{ }\end{array}$ & $\begin{array}{l}0600 \text { Hrs. }-0800 \\
\text { Hrs. } \\
\sqrt{ }\end{array}$ \\
\hline 0900 Hrs. -1200 Hrs. & $\begin{array}{lr}0800 & \text { Hrs. } \\
- & 1200 \\
\text { Hrs. } & \\
\end{array}$ & $\begin{array}{l}0800 \text { Hrs. }-1200 \\
\text { Hrs. }\end{array}$ & $\begin{array}{l}0800 \text { Hrs. }-1200 \\
\text { Hrs. }\end{array}$ \\
\hline 1800 Hrs. -2200 Hrs. & $\sqrt{ }$ & $\sqrt{ }$ & $\sqrt{ }$ \\
\hline
\end{tabular}

Table 3: Observed Load Curve for Winter Season

\begin{tabular}{|c|c|c|c|}
\hline Existing ToD Slots of MSEDCL & \multicolumn{3}{|c|}{ Observed period of variation in load curve } \\
\hline Time Slots in Hours & Din Dayal Nagar & Trimurti Nagar & $\begin{array}{l}\text { Congress } \\
\text { division }\end{array}$ \\
\hline 2200 Hrs. -0600 Hrs. & $\sqrt{ }$ & $\sqrt{ }$ & $\sqrt{ }$ \\
\hline $\begin{array}{l}0600 \text { Hrs. }-0900 \text { Hrs. } \\
1200 \text { Hrs. }-1800 \text { Hrs. }\end{array}$ & $\begin{array}{l}0600 \text { Hrs. }-0800 \\
\text { Hrs. } \\
\sqrt{ }\end{array}$ & $\begin{array}{l}0600 \text { Hrs. }-0800 \\
\text { Hrs. } \\
\sqrt{ }\end{array}$ & 0600 Hrs. -0800 Hrs. \\
\hline 0900 Hrs. -1200 Hrs. & $\begin{array}{l}0800 \text { Hrs. }-1200 \\
\text { Hrs. }\end{array}$ & $\begin{array}{l}0800 \text { Hrs. }-1200 \\
\text { Hrs. }\end{array}$ & 0800 Hrs. -1200 Hrs. \\
\hline 1800 Hrs. -2200 Hrs. & $\sqrt{ }$ & $\sqrt{ }$ & $\sqrt{ }$ \\
\hline
\end{tabular}

Table 4: Observed Load Curve for Rainy Season

\begin{tabular}{|c|c|c|c|}
\hline Existing ToD Slots of MSEDCL & \multicolumn{3}{|c|}{ Observed period of variation in load curve } \\
\hline Time Slots in Hours & Din Dayal Nagar & Trimurti Nagar & $\begin{array}{ll}\begin{array}{l}\text { Congress } \\
\text { division }\end{array} & \text { Nagar } \\
\end{array}$ \\
\hline 2200 Hrs. -0600 Hrs. & 0600 Hrs. -1300 Hrs. & 0600 Hrs. -1300 Hrs. & 0600 Hrs. -1300 Hrs. \\
\hline $\begin{array}{l}0600 \text { Hrs. }-0900 \text { Hrs. } \\
1200 \text { Hrs. }-1800 \text { Hrs. }\end{array}$ & $\begin{array}{l}0300 \text { Hrs. }-0600 \text { Hrs. } \\
1800 \text { Hrs. }-2200 \text { Hrs. }\end{array}$ & $\begin{array}{l}0300 \text { Hrs. }-0600 \text { Hrs. } \\
1800 \text { Hrs. }-2200 \text { Hrs. }\end{array}$ & $\begin{array}{l}0300 \text { Hrs. }-0600 \text { Hrs. } \\
1800 \text { Hrs. }-2200 \text { Hrs. }\end{array}$ \\
\hline 0900 Hrs. -1200 Hrs. & 1300 Hrs. -1800 Hrs. & 1300 Hrs. -1800 Hrs. & $\begin{array}{l}1300 \text { Hrs. }-1800 \text { Hrs. } \\
\text { (AP) }\end{array}$ \\
\hline 1800 Hrs. -2200 Hrs. & 2200 Hrs. -0300 Hrs. & 2200 Hrs. -0300 Hrs. & $\begin{array}{l}2200 \quad \text { Hrs. } \\
\text { Hrs.(NP) }\end{array}$ \\
\hline
\end{tabular}

\begin{tabular}{|c|c|c|}
\hline Seasons & Summer Season & Winter \& Rainy Season \\
\hline & Proposed Time Slots in Hours & Proposed Time Slots in Hours \\
\hline Off Load Period (OLP) - (Rebate) & 0600 Hrs. -1300 Hrs. & 2200 Hrs. -0600 Hrs. \\
\hline Base Period (BSP) - (Base rate) & $\begin{array}{l}0300 \text { Hrs. }-0600 \text { Hrs. } \\
1800 \text { Hrs. }-2200 \text { Hrs. }\end{array}$ & $\begin{array}{l}0600 \text { Hrs. }-0800 \text { Hrs. } \\
1200 \text { Hrs. }-1800 \text { Hrs. }\end{array}$ \\
\hline Morning Peak Load (MLP) - (Penalty) & 1300 Hrs. -1800 Hrs. (AP) & 0800 Hrs. -1200 Hrs. \\
\hline Evening Peak Load (ELP) - (Penalty) & 2200 Hrs. -0300 Hrs.(NP) & 1800 Hrs. -2200 Hrs. \\
\hline
\end{tabular}

Table 6: Proposed ToD Slots (Season Wise)

\section{Conclusion}

This paper has presented an overview of existing electricity tariff structure \& residential load pattern in Maharashtra state. Also discusses a case study which present a comparison between the actual load pattern of residential consumers with existing ToD slots 
of MSEDCL for LT - II (B) non-residential. It is observed that $90 \%$ of the residential load consumption curve in winter and rainy seasons is similar to the MSEDCL's ToD slots of LT - II (B) non-residential consumers; therefore, slight modifications are suggested in winter and rainy seasons if $\mathrm{ToD}$ is implemented to residential consumers. For both the seasons, proposed time slots will remain same. Whereas, in the summer season, the scenario is totally different, hence new slots are proposed.

\section{References}

1. “Electricity Act 2003" No. 36 of 2003 [Online]. Available: http://cercind.gov.in/Act-with-amendment.pdf

2. "National
https://powermin.nic.in/sites/default/files/webform/notices/Proposed_amendments_in_Tariff_Policy_0.pdf

3. "MERC Order - Case No. 195 of 2017" [Online]. Available: $\bar{h}$ https://www.mahadiscom.in/wpcontent/uploads/2018/07/Petition-Part-I-Main-Petition.pdf

4. “Central Electricity Regulatory Commission" [Online]. Available: http://www.cercind.gov.in/

5. The Gazette of India, Extraordinary Part I - Section I, Published by Ministry of Power, Tariff Policy No. 23/2/2005 - R \& R (vol. III). 6th January, 2006.

6. "Maharashtra State Electricity Distribution Company Limited" [Online]. Available: http://www.mahadiscom.in/daily-powerposition/

7. MERC Order for Tariff determination of FY 2012-13 Case No. 19 of 2012.

8. R.Kadam, S. Rokade and R. Holmukhe. 2013. Overview of Demand Response Options and Regulatory Initiatives from Maharashtra Perspective. IEEE ISGT Asia, 1-6.

9. “MSEDCL Circular no. 302” [Online]. Available: https://www.mahadiscom.in/consumer/wpcontent/uploads/2018/04/Comm_Cir_302.pdf

10. A. S. Talhar, S.B. Bodkhe. 2019. Study and Analysis of Dynamic Pricing in India and Proposing for Residential Consumers in Maharashtra. Helix - The Scientific Explore. 9:4870 - 4877.

11. A. S. Talhar, S.B. Bodkhe. 2019. Study and Implementation of the Real Time Tariff for Residential Load in Other Countries and Proposing the Same for India. International Journal of Innovative Technology and Exploring Engineering. 8:282 - 287.

12. "Reliance Power" [Online]. Available: https://www.reliancepower.co.in/

13. "TATA Power" [Online]. Available: https://www.tatapower.com/

14. "BEST Power" [Online]. Available: https://www.bestundertaking.com/in/main.asp?m=Electricity

15. "Feeder Data MSEDCL" [Online]. Available: https://consumerinfo.mahadiscom.in/feeder/feeder_outage.php 